SiF 2020- The $11^{\text {th }}$ International Conference on Structures in Fire

The University of Queensland, Brisbane, Australia, November 30-December 2, 2020

\title{
NUMERICAL INVESTIGATION OF THE STRUCTURAL RESPONSE OF ECCENTRICALLY LOADED REINFORCED CONCRETE COLUMNS EXPOSED TO NON-UNIFORM HEATING AND COOLING
}

\author{
Patrick Bamonte ${ }^{1}$, Nataša Kalaba ${ }^{2}$, Jamie Maclean ${ }^{3}$, Luke Bisby ${ }^{4}$
}

\begin{abstract}
This paper explores the applicability of advanced numerical models to the complex structural behaviour observed when symmetrically reinforced and eccentrically loaded concrete columns are subjected to nonuniform heating regimes. To this end, attention is focused on a recently completed experimental campaign specifically aimed at providing a novel data set on the performance of reinforced concrete members subjected to several combinations of loading, heating, and cooling conditions. The structural behaviour of the columns was studied using 3D finite element models developed using commercial software by means of sequentially-coupled thermomechanical analyses. A user subroutine was developed to model the mechanical properties as irrecoverable in the cooling phase. The results obtained show that, on the whole, the structural behaviour can be adequately represented by the numerical model. Moreover, the roles of thermal and transient deformations are correctly captured, as well as the possibility of failure in the cooling phase.
\end{abstract}

Keywords: Reinforced concrete columns; finite element modelling; cooling

\section{INTRODUCTION}

Concrete modelling at high temperature is not an easy task due to the highly nonlinear material and structural behaviour. When irrecoverable deformations at the material level take place, it is required to perform plastic analyses and, consequently, to resort to advanced constitutive models implemented in finite element codes. When beams and columns are at issue, numerical modelling via beam finite elements (Bamonte and Lo Monte, 2015; Gernay, 2019) can be carried out by means of uniaxial constitutive laws, such as those provided in the pertinent standards (e.g. EN 1992-1-2, 2004). On the other hand, when more complex structural members (such as slabs, walls and tunnel linings) are considered, 2D or 3D finite elements analyses must be carried out, thus requiring the definition of concrete behaviour for multiaxial states of stresses. Numerical models that use 3D Finite Elements are the most complex models for structural analysis. They require significant computational and modelling effort and should be used with care. In the case where the local behaviour of RC structures exposed to fire is the main goal of the investigation, a 3D finite elements model can be a very efficient tool. In addition, non-

\footnotetext{
${ }^{1}$ Associate Professor of Structural Analysis and Design, Politecnico di Milano, Milan, Italy e-mail: patrick.bamonte@polimi.it, ORCID: http://orcid.org/0000-0002-4967-1089

${ }^{2}$ Structural Fire Engineer, CERIB, Epernon, France

e-mail: N.KALABA@cerib.com

${ }^{3}$ Senior Sofware Developer, UFirstGroup, Spain

e-mail: jamie.maclean@ufirstgroup.ch

${ }^{4}$ Chair of Fire and Structures, School of Engineering, University of Edinburgh, Edinburgh, UK

e-mail: Luke.Bisby@ed.ac.uk, ORCID: https://orcid.org/0000-0001-8293-4322
} 
uniform heating (e.g. localized heating), when the heat transfer along the length of the member is important, modelling bond-slip or localized spalling (if possible) requires considering the whole volume of the structural member and modelling it in the 3D space.

This paper explores the applicability of advanced numerical models to the complex structural behaviour observed when symmetrically reinforced and eccentrically loaded concrete columns are subjected to nonuniform heating regimes. To this end, attention is focused on a recently completed experimental campaign specifically aimed at providing a novel data set on the performance of reinforced concrete columns subjected to several combinations of loading, heating, and cooling conditions. The structural behaviour of the columns was studied using 3D finite element models developed using ABAQUS by means of sequentially-coupled thermomechanical analyses. Attention will be focused on the role played by different parameters, which were varied during the tests, namely load magnitude, eccentricity of the applied load, concrete compressive strength, magnitude of applied initial incident radiant heat flux, overall length of the heated area, and fire exposure.

\section{EXPERIMENTAL CAMPAIGN}

\subsection{General description}

The reference experimental database considered consists of 46 nominally-identical reinforced concrete columns tested at the University of Edinburgh (Maclean, 2018; Maclean and Bisby, 2020). The dimensions of the specimens are shown in Figure 1a. All the tested columns had identical geometry, with dimensions of the cross section $150 \times 150 \mathrm{~mm}^{2}$ and overall length of $1400 \mathrm{~mm}$. The columns were all pinned-pinned and reinforced with $4 \mathrm{H} 10$ longitudinal bars (distance between the axes $=90 \mathrm{~mm}$ ) and 10H6 closed stirrups $($ spacing $=140 \mathrm{~mm}$ ). 36 columns have been tested while exposed to fire, while 10 columns have been tested at ambient temperature, to determine the reference load capacity. Concrete strength at the test day was 30 and $50 \mathrm{MPa}$ for the two mixes considered. Both mixes contained $2 \mathrm{~kg} / \mathrm{m}^{3}$ of polypropylene fibres, to minimize the likelihood of spalling.

In the experimental campaign, the influence of various parameters on the columns' performance during heating and during/after cooling has been investigated:

- load magnitude: severe loading and low loading were considered - $60 \%$ of the ambient load capacity or a constant load of $10 \mathrm{kN}$ (equivalent to $1-2 \%$ of the columns ambient capacity), respectively;

- eccentricity of the applied load: 5,15 or $25 \mathrm{~mm}$;

- concrete compressive strength: 30 or $50 \mathrm{MPa}$;

- magnitude of applied initial incident radiant heat flux: 0,50 or $70 \mathrm{~kW} / \mathrm{m}^{2}$;

- overall length of the heated area $-33 \%$ of the length (middle third) or $66 \%$ of the column length;

- number and sides exposed to fire (one side or two sides) - the heated sides were front and back of the columns;

Before presenting the results, it is important to explain denomination of the tested columns (MacLean, 2018). For instance, the test HF70-F30-L60-E25-C stands for the column exposed to a heat flux of $70 \mathrm{~kW} / \mathrm{m}^{2}$ (HF70), having a compressive strength $\mathrm{f}_{\mathrm{c}}=30 \mathrm{MPa}(\mathrm{F} 30)$, loaded with an axial force equal to $60 \%$ of its axial capacity (L60) applied with eccentricity of $25 \mathrm{~mm}$ (E25). Finally, C denotes the side heated - compression $(\mathrm{C})$ or tension $(\mathrm{T})$ heated side.

\subsection{Heating of the columns}

The columns were heated by using radiant panels (Figure 1a and $b$ ). The panels could be placed at a specified distance from the member, in order to achieve the desired value of the incident radiant heat flux. Only a portion of the column was directly heated, while in the areas of the member away from the heated surface area, heat transfer was governed by conduction through the concrete itself, rather than radiation from the panels (as well as convective losses from exposed surfaces). It is worth observing that such setup leads to a non-uniform distribution of incident heat flux over the exposed surface of the column, which is 
due to the variation of the view factor at any particular location on the heated surface and the interaction of the surface with convective currents generated both by the radiant panels themselves and by the heated face of the column. The radiant panels had a rectangular shape; therefore, the plane of incident radiant heat flux, which represents a specific desired peak value (for example, $50 \mathrm{~kW} / \mathrm{m}^{2}$ or $70 \mathrm{~kW} / \mathrm{m}^{2}$ in the experimental campaign) at the location of maximum heat flux at a specified offset distance will actually represent a variable incident radiant heat flux distribution over the target surface.

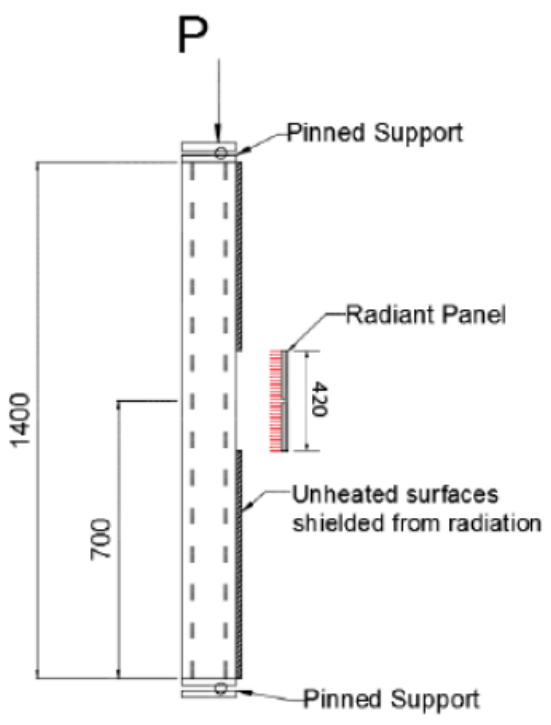

(a)

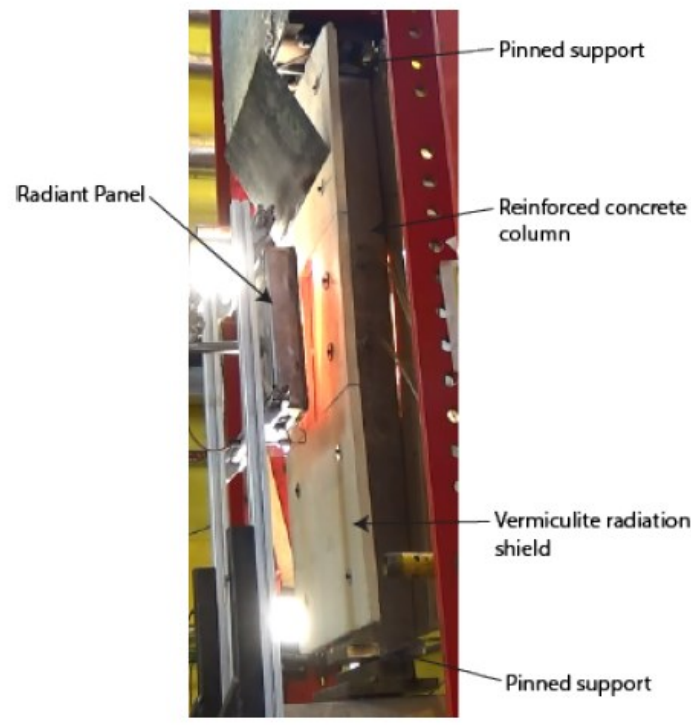

(b)

Figure 1. (a) Geometry of a typical column specimen; (b) photo of test set-up

\section{NUMERICAL MODELLING}

\subsection{General}

The columns tested at the University of Edinburgh were analysed by means of sequentially-coupled thermo-mechanical analyses performed by means of the commercial finite element software ABAQUS 6.19. The first step consists in solving the heat transfer problem. Afterwards, the temperature output is used in a mechanical analysis as a predefined field. Therefore, two sub-models are built: a model for the thermal analysis and a model for the mechanical analysis. Nodal temperatures are stored as a function of time in the output results. The temperatures in the member act as thermal body-load in the structural model, and are applied together with the mechanical loading in the subsequent mechanical analysis. Longitudinal reinforcing bars and stirrups were included in both models.

\subsection{Thermal analysis}

Linear brick elements with eight nodes (DC3D8) are used for concrete, while reinforcing bars are discretized using linear elements with two nodes (DC1D2). These elements have the nodal temperature as the only active degree of freedom. Concrete-rebar interface is modelled using a tie constraint, to enforce a unique temperature at the nodes shared between steel and concrete.

In order to properly model the heat exposure, a user subroutine (DFLUX) was used to calculate the net incident heat flux on the heat-exposed surface of the member as a function of time, while in the cooling phase the applied heat flux is equal to zero. The subroutine is called at each integration point whenever a surface-based non-uniform distributed heat flux is defined in the analysis. The net incident heat flux is calculated according to the provisions of EN 1991-1-2 (2002). The subroutine DFLUX requires the definition of two values: FLUX(1) is the value of the applied heat flux, namely the magnitude of the flux flowing into the point as a function of time and space, while $\operatorname{FLUX}(2)$ is the derivative of the heat flux 
with respect to surface temperature. In the case under consideration, the incident heat flux varies over the exposed surface. The maximum values of the incident radiant heat fluxes to which the columns were exposed are 50 and $70 \mathrm{~kW} / \mathrm{m}^{2}$, but these values are not constant over the exposed surface. This variable spatial distribution of the heat flux on the exposed surface was not taken into account. For this reason, the two reference values of the heat flux, 50 and $70 \mathrm{~kW} / \mathrm{m}^{2}$, were reduced to 42 and $60 \mathrm{~kW} / \mathrm{m}^{2}$, respectively, to obtain a reasonably accurate fit between the predicted temperature at the heat-exposed side and the experimentally measured value.

Heat transfer inside the member takes place through conduction. At the boundaries of the heat-exposed surfaces, convection with convective coefficient of $25 \mathrm{~W} /\left(\mathrm{m}^{2} \cdot \mathrm{K}\right)$ is assumed, while for the unexposed surfaces the convective coefficient is set to $9 \mathrm{~W} /\left(\mathrm{m}^{2} \cdot \mathrm{K}\right)$, accounting for the radiation. Radiation with emissivity $\varepsilon=0.7$ was assumed for all the heat exposed concrete surfaces. Thermal properties of concrete and steel are assumed as per EN 1992-1-2 (2004). An exemplary temperature distribution in the column at the end of the heating phase (90 minutes) is shown in Figure 2.

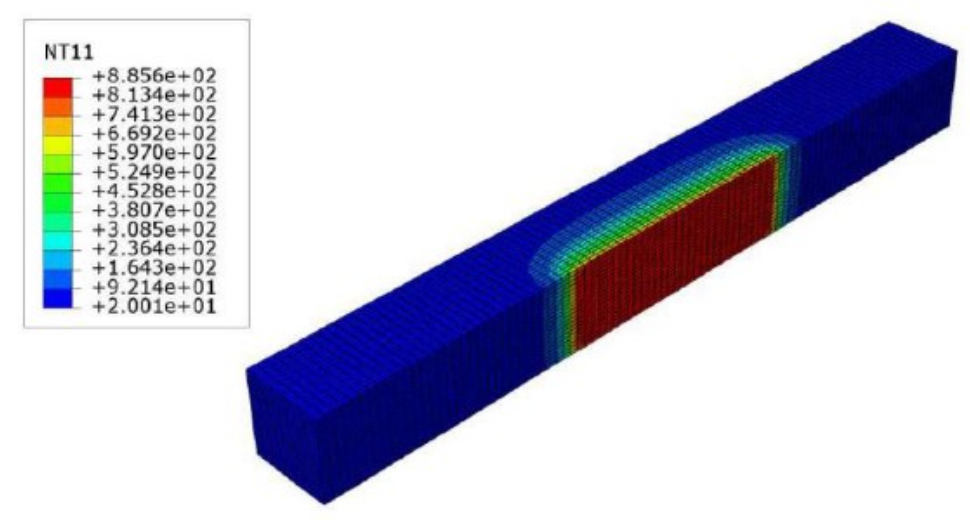

Figure 2. Temperature distribution in the column at 90 minutes of heat exposure

\subsection{Mechanical analysis}

The model for the mechanical analysis was built using 3D stress-displacements elements for the discretization of concrete and steel rebars. Concrete is discretized using 8-node linear-brick elements (C3D8), with translations in the three directions as active degrees of freedom at each node. This element type can be used for modelling of solids with or without reinforcement, and it is capable of accounting for cracking of concrete in tension and crushing of concrete in compression, creep and large strains. Steel rebars are discretized with 2-noded linear displacement truss elements (T3D2), which deform by axial elongation only. When the strains are large, the formulation is simplified by assuming that the trusses are made of incompressible material. This approach has been used to model the reinforcement where the nodes of reinforcement are coincident with the nodes of concrete. Concrete-rebar interface is modelled with embedded region constraint, i.e. no slip is allowed (perfect bond is assumed).

Decay of the mechanical properties at elevated temperature for concrete and reinforcing steel is taken as per EN 1992-1-2. In the cooling phase, the properties are considered as irrecoverable, to account for the irreversible thermal damage in the material. This has been done by implementing a FORTRAN user subroutine - UFIELD, which allows updating the mechanical properties only in the heating phase, when the temperature in the current time increment is higher than the temperature in the previous time increment. If the material is in the cooling phase, its mechanical properties retain the value they had at the maximum temperature, i.e. the behaviour is governed by the maximum temperature reached and not by the current temperature. Finally, definition of material properties in the software requires the definition of temperature dependent elastic properties as well as the definition of the plastic model (Kalaba, 2019). 
Regarding the boundary conditions, two reference points are created, at a small distance from the column member, and then kinematically coupled with the surface of the column. Restraint conditions (pinned ends) and external loads are then applied directly to the two reference points (Figure 2).

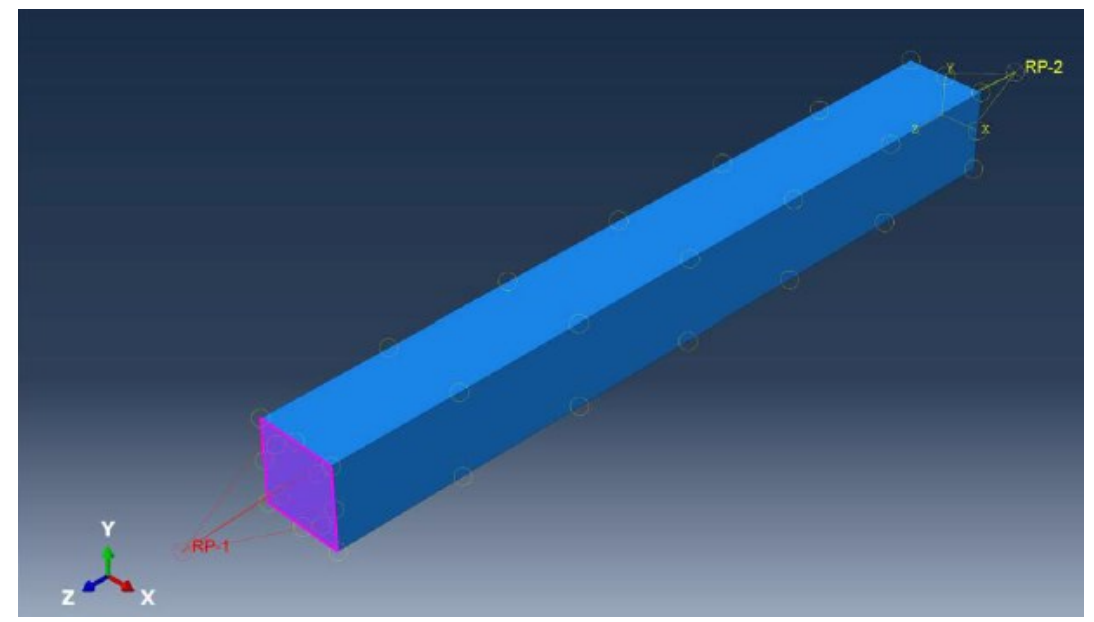

Figure 3. Definition of the mechanical boundary conditions for the columns: reference points kinematically coupled with the column surface

\section{NUMERICAL RESULTS}

\subsection{Columns of the $1^{\text {st }}$ Group}

All the columns that belonged to this group had a compressive strength $f_{c}=30 \mathrm{MPa}$ and were exposed to a heat flux $70 \mathrm{~kW} / \mathrm{m}^{2}$. Load level, side exposed to fire and eccentricity of the applied load varied.

Applying the lower load on the columns helps to understand the extent of the irrecoverable deformation that takes place upon cooling back to ambient temperature. In case that a low load, equal to 1-2\% of the load capacity, is applied, it would be expected that the thermal expansion governs the deflection response. In case of low load eccentricity, lateral deflection and bowing take place due to thermal expansion.

Looking at Figure 4, the displacement response can be divided into three stages: initial bowing towards the heat source, governed by the thermal expansion, followed by the contraction of the columns, and the ensuing bowing direction reversal. The last stage of the cooling phase brings in some stabilization of the deflections, when the values keep almost constant values (from around 200 minutes onwards). The maximum deflection is reached soon after the heating phase has ended (after 90 minutes). Slight differences in the response can be observed for a varying eccentricity (Figure 4b). For a $25 \mathrm{~mm}$ load eccentricity, tension-heated columns deflect more than compression-heated columns.

There is no full recovery to the initial values upon cooling: the measured residual deflection is around $1 \mathrm{~cm}$. While the overall trend is well reproduced by the numerical model, the displacements are very conservative in the later stages of the heating phase and then in the subsequent cooling phase of fire. The numerical model predicts a certain amount of irrecoverable deformation which was not measured in the tests. As pointed out by MacLean (2018), thermal expansion of tension-heated columns together with the moment induced by the eccentric load, increases the deflection of the column. This increase in deflection would then induce secondary moments, increasing the moment in the section even farther. In compression-heated columns the opposite is valid: deflections due to thermal expansion reduce the moment in the section, resulting in smaller deflections in comparison to tension-heated columns. Still, the fact that tension-heated columns deflect more than compression-heated columns might have been caused by the higher temperatures experienced in those members, given that during the fire they deflect towards the heat source, thereby increasing the heat flux on the exposed side with respect to compression-heated columns. This effect is not captured in the numerical analyses, as the basic premise of the sequentiallycoupled thermo-mechanical analyses is that the thermal field is not dependent on the displacement/stress field. 

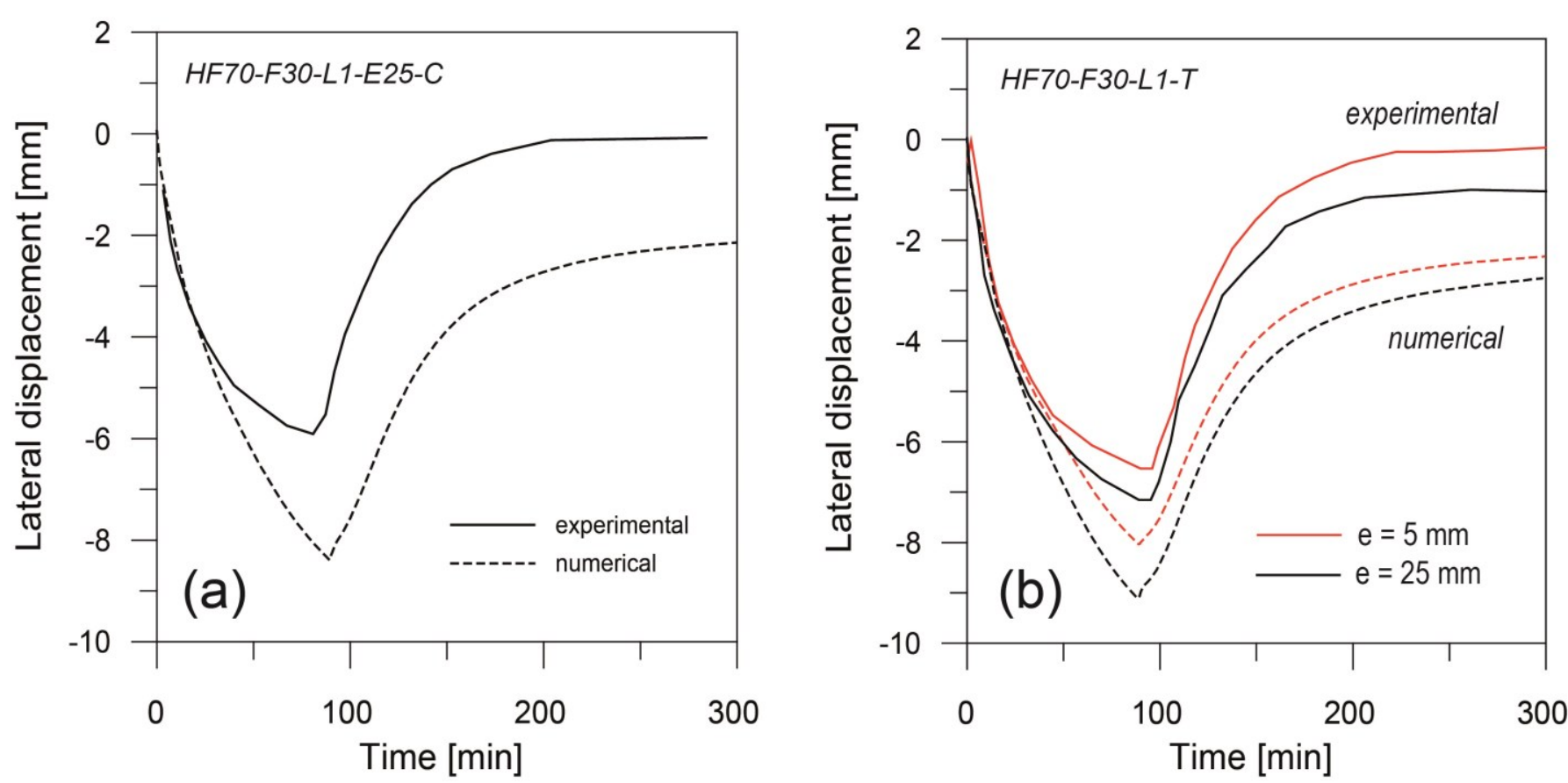

Figure 4. Comparison between experimental and numerical midspan deflection evolution in: (a) compression-heated columns with $\mathrm{e}=25 \mathrm{~mm}$ and (b) tension-heated columns with $\mathrm{e}=25 \mathrm{~mm}$ and $\mathrm{e}=5 \mathrm{~mm}$ (continuous lines $=$ experimental results; dashed lines $=$ numerical results)

Columns tested under higher loads exhibit a different structural response than the columns tested under low loads (Figure 5). At the beginning of the test, compression-heated columns bow away from the heat source, as the effect of the load dominates the response (Figure 5a). Unexpectedly, the column continues to deflect away from the heat source even after the end of the heating phase. This can be explained with the effect of transient creep strain, resulting in contraction rather than expansion. Upon removal of the heating panels (after approximately 90 minutes), the columns deflect rapidly away from the heat source, until failure or attainment of a new state of equilibrium. Deflections are not recovered during cooling. Instead, after around 180 minutes into the fire, the deflections stabilized and kept almost a constant value until the end of the test. Numerically, the general trend is well reproduced. The column failed for the eccentricity e $=25 \mathrm{~mm}$, after around 260 minutes (in the cooling phase of fire), which is just slightly non conservative in comparison to the failure time measured during the test. On the other hand, the column survived the fire for lower eccentricity, thanks to the smaller bending moments and thus smaller deflections and less pronounced second-order effects; the predicted displacements follow closely the experimental curve. Residual deflection obtained numerically is around $16 \mathrm{~mm}$ while experimentally measured value was $14.7 \mathrm{~mm}$.

Tension-heated columns with lower eccentricity (Figure $5 \mathrm{~b}$ ) behave in a similar way to compressionheated columns (Figure 5a). The behaviour during the heating phase and the stabilization of the deflection in the later stages of the cooling phase is correctly captured by the model. However, the same cannot be said for the tension-heated column with the higher load eccentricity (Figure 5c): the effect of thermal expansion prevails, due to low compressive stresses at the heated face, resulting in overall smaller deflections than for the lower eccentricity case. Numerical model was not able to capture the experimentally observed behaviour during the cooling phase, where there was almost no recovery in the deflections. The numerical model underestimated the residual deflections measured during the test, while the maximum deflection measured at the end of the heating phase was somewhat conservative. 

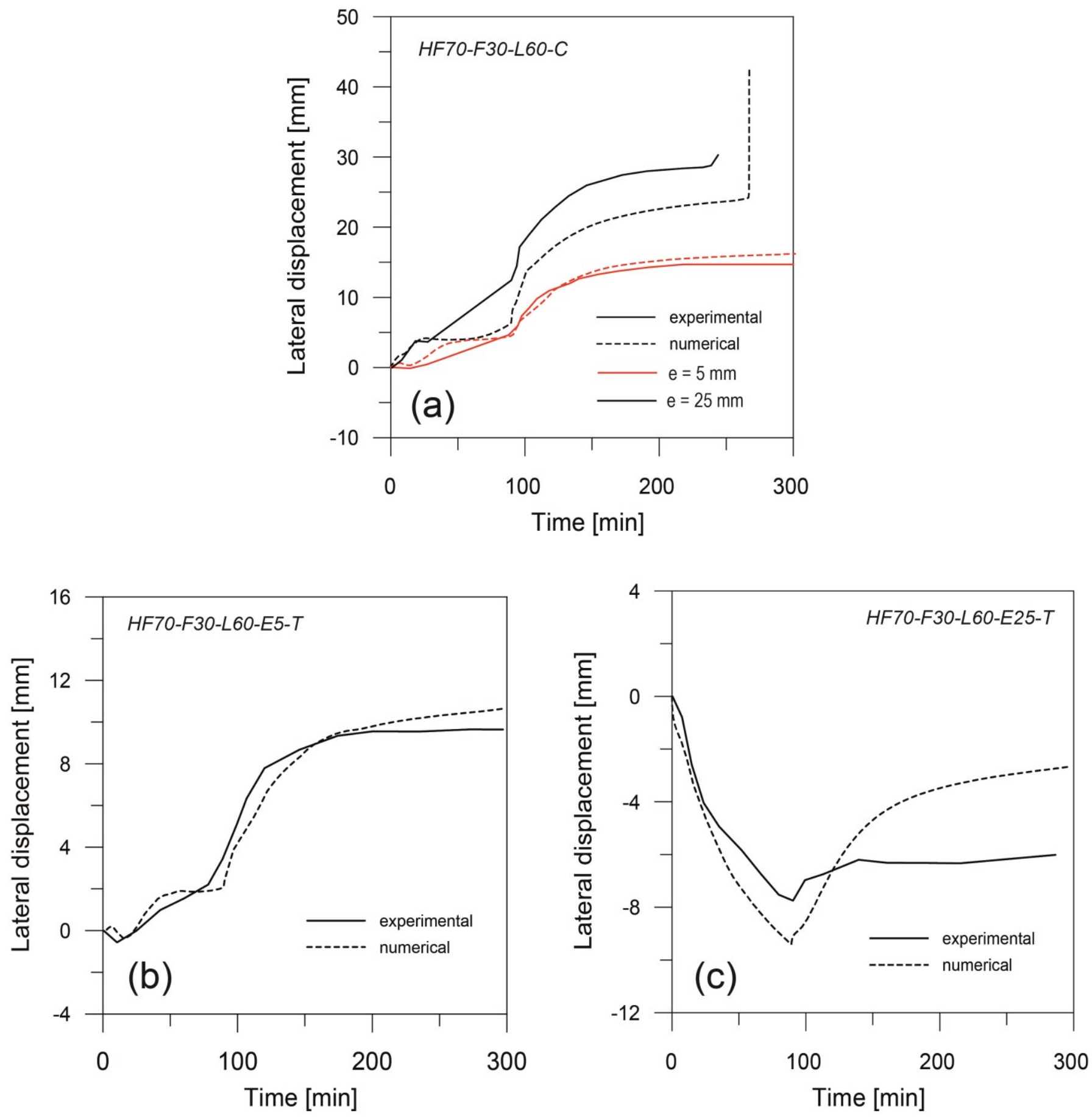

Figure 5. Comparison between experimental and numerical midspan deflection evolution for heavily loaded columns: (a) tension-heated, $\mathrm{e}=5 \mathrm{~mm}$; (b) tension-heated, $\mathrm{e}=25 \mathrm{~mm}$ and (c) compression-heated, $\mathrm{e}=5 \mathrm{~mm}$ and e $=25 \mathrm{~mm}$

\subsection{Columns of the $2^{\text {nd }}$ Group}

All the columns that belong to this group had a compressive strength $f_{c}=30 \mathrm{MPa}$, were exposed to a heat flux $50 \mathrm{~kW} / \mathrm{m}^{2}$ and loaded with an axial force equal to $60 \%$ of their axial load capacity. The side exposed to fire and load eccentricity varied.

During the tests, it was observed that decreasing the heat flux to $50 \mathrm{~kW} / \mathrm{m}^{2}$ did not change the general trend in the deflection evolution: it produces similar but less severe and less pronounced response compared to a higher heat flux of $70 \mathrm{~kW} / \mathrm{m}^{2}$. This is expected because decreasing the heat flux will lead to a similar thermal field inside the member, with lower values of the maximum temperature and thus less significant damage inside the member. 
Tension-heated specimen bows towards the heat source in the first 20 minutes of fire, and then the deflection trend reverses, and the columns bow away from the heat source for the remaining duration of fire. Displacement of tension heated columns is overestimated by the model. General trend suggests that the displacements are monotonically increasing (though at a lower rate during cooling phase, i.e. after $150 \mathrm{~min}$ ) while during the test displacements were almost constant after $150 \mathrm{~min}$ of fire.

Compression-heated columns deflect away from the heat source during the whole fire duration (Figure 6b). Columns from Group 1, exposed to a heat flux of $70 \mathrm{~kW} / \mathrm{m}^{2}$, exhibited more significant damage and deflections than columns from Group 2. This is probably due to transient thermal creep caused by the higher temperatures at the exposed side. The predicted displacement is slightly underestimated in the case of compression-heated columns loaded with the eccentricity of e $=25 \mathrm{~mm}$, while in the case of lower eccentricity, the displacements are well predicted, during both heating and cooling phase of the fire (Figure 6b).
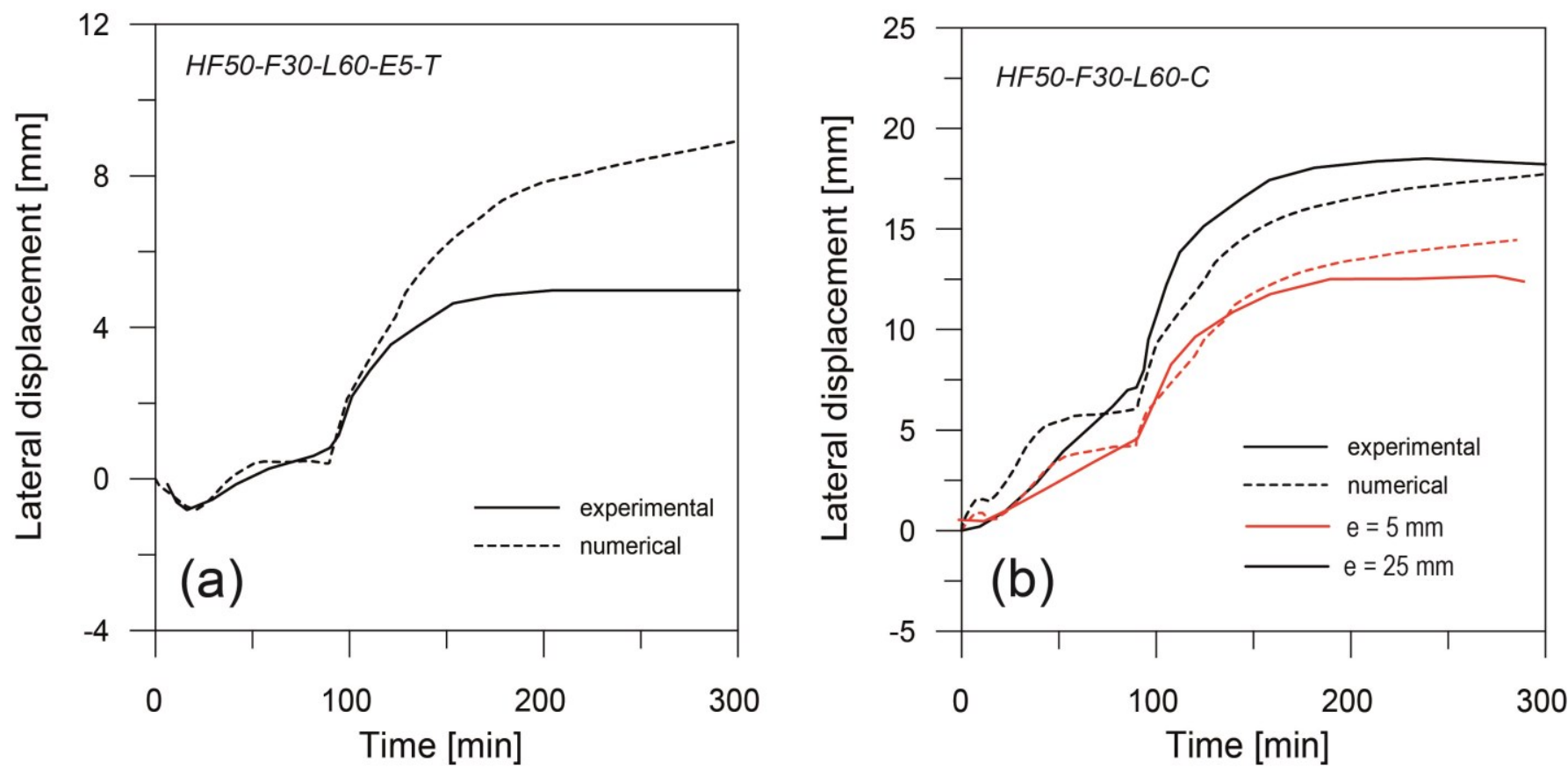

Figure 6. Comparison between experimental and numerical midspan deflection evolution for heavily-loaded columns, with heat flux of $50 \mathrm{~kW} / \mathrm{m}^{2}$ : (a) tension-heated columns with e $=5 \mathrm{~mm}$ and (b) compression-heated columns with e $=5 \mathrm{~mm}$ and e $=$ $25 \mathrm{~mm}$

\subsection{Columns of the $3^{\text {rd }}$ Group}

All the columns that belonged to this group had a compressive strength $f_{c}=50 \mathrm{MPa}$ and were exposed to a heat flux of $70 \mathrm{~kW} / \mathrm{m}^{2}$. Load level, side exposed to fire and eccentricity of the applied load varied.

The columns deform towards the heat source for the whole duration of the heating-cooling cycle. In the first 90 minutes of heating, the displacement is increasing towards the heat source. Upon cooling, the deflection trend reverses, and the columns deform away from the heat source. Both compression-heated and tension-heated columns behave in a similar way, except that compression-heated columns recovered the deflections to the initial values, while tension-heated columns had some residual deflection left. Comparing the response of the columns with different compressive strength shows significant differences, as expected.

The comparison is first carried out for columns loaded with low load, where its influence is minimal and the deflections are expected to be fully recovered upon cooling (transient strain is not taking place). In the tests, columns with compressive strength $\mathrm{f}_{\mathrm{c}}=30 \mathrm{MPa}$ deflected less than columns with compressive strength $f_{c}=50 \mathrm{MPa}$, which is somewhat counter-intuitive, especially given the fact that same low load 
was applied to all the columns. This may suggest that stronger columns suffered more pronounced thermal expansion but this could not be verified during the experimental campaign. However, an opposite trend is obtained in the model - stiffer and stronger columns indeed deformed less, both in terms of peak deflection and also in the residual stage (Figure 7).

Columns exposed to low load exhibited lateral deflections and bowing almost immediately after being exposed to fire, due to thermal gradients developing through the depth of the column section. While the numerical model has been able to capture the general trend as well as to predict the maximum deflection at the end of the heating phase, it proved to be more conservative during the cooling phase. It predicted certain amount of residual deflections in compression-heated columns, while in the tests an almost complete deflection recovery was observed (Figure 7a). On the other hand, deflections during cooling for tension-heated columns are well predicted, while during heating phase they are slightly underestimated (Figure $7 b$ ).
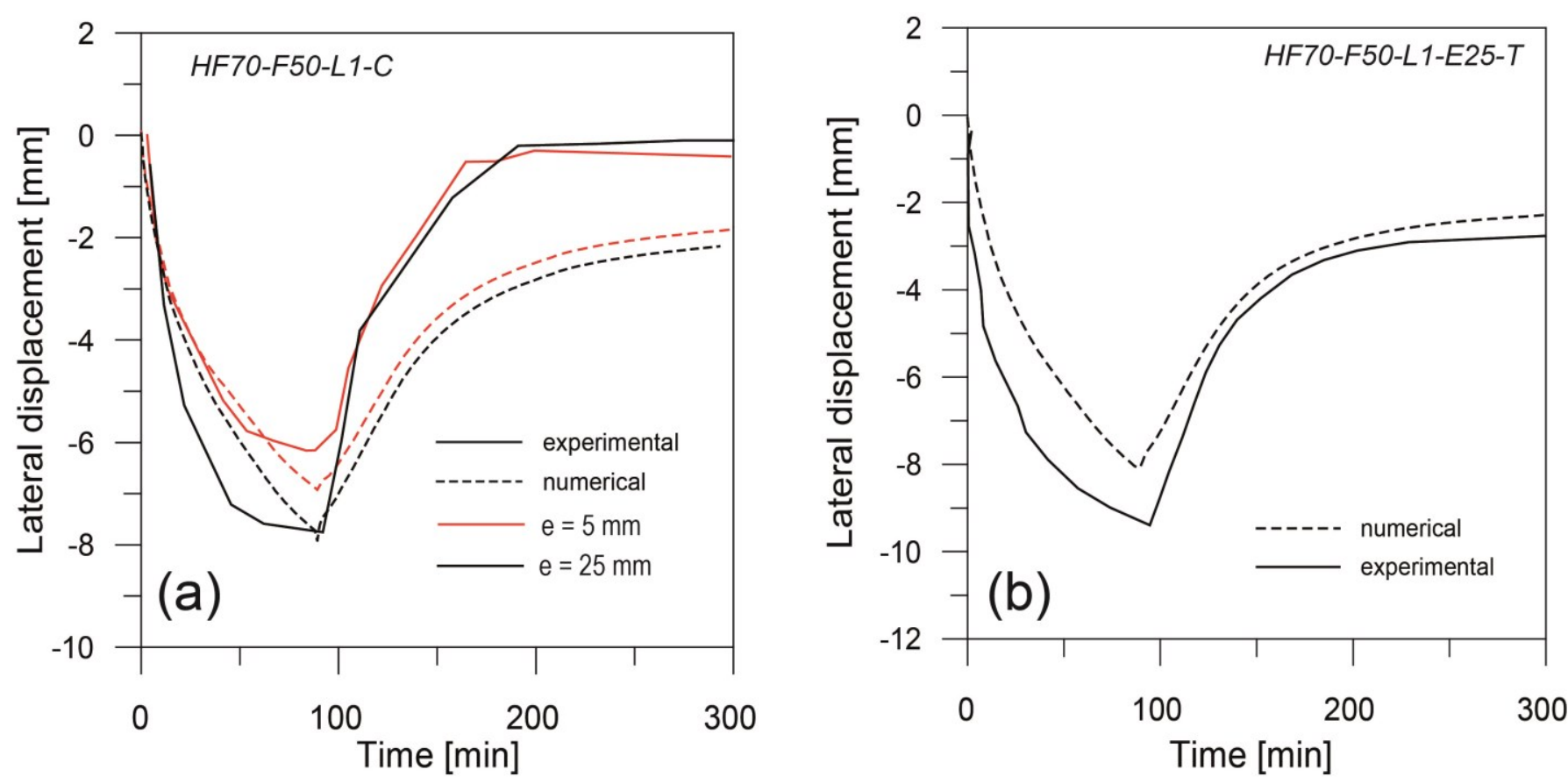

Figure 7. Comparison between experimental and numerical lateral midspan deflection evolution for low-loaded columns, with compressive strength $\mathrm{f}_{\mathrm{c}}=50 \mathrm{MPa}$ : (a) compression-heated, e $=5 \mathrm{~mm}$ and e $=25 \mathrm{~mm}$ and (b) tension-heated, $\mathrm{e}=25 \mathrm{~mm}$

While the load level proved to be a significant factor, compressive strength proved to play less important role in view of the deflection evolution. It is true that the columns of different strength deform to a different extent but this is in part due to the different load applied. Compression-heated specimens deflect away from the heat source due to the transient creep strain while tension-heated specimens bend towards the heat source due to thermal expansion of the extreme fibre of the heated face. The behaviour of compression-heated columns is well simulated and failure time is predicted well, only slightly on the nonconservative side (Figure 8).

Deflection of the tension-heated column is predicted accurately for lower eccentricity, when the columns bows away from the heat source, due to the influence of applied load and stresses on the heated side. On the other hand, for higher eccentricity the influence of thermal expansion dominates the response, because compressive stresses in the heat exposed side are low and cannot counteract the thermal expansion. Thus, the column bows towards the heat source. 

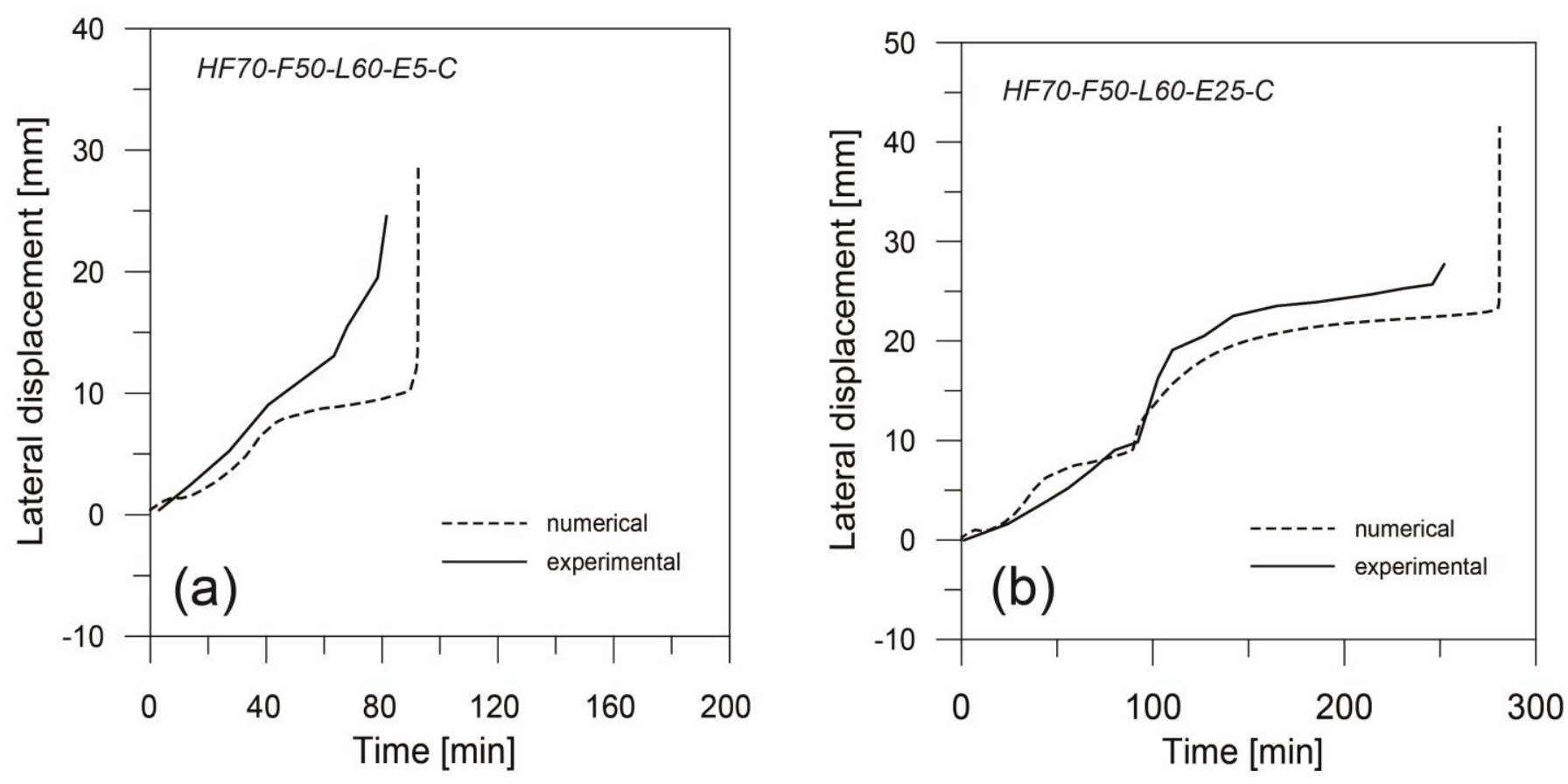

Figure 8. Comparison between experimental and numerical midspan deflection evolution for heavily loaded columns with compressive strength $\mathrm{f}_{\mathrm{c}}=50 \mathrm{MPa}$ : (a) compression-heated, e $=5 \mathrm{~mm}$, and (b) compression-heated, e $=25 \mathrm{~mm}$

The general trend is well predicted by the model, but the displacements in the cooling phase are somewhat underestimated (Figure 9). Compression-heated columns are heated on the most stressed section, the extent of the transient creep and therefore the magnitude of the deflections depends on the magnitude of the load - higher loads lead to higher compressive stresses and thus to higher deflections (away from the heat source) due to transient thermal creep strain. Being exposed to higher loads than the corresponding columns from the $1^{\text {st }}$ Group (with $\mathrm{f}_{\mathrm{c}}=30 \mathrm{MPa}$ ), they deflect more and their deflection response is more sizable. Tension-heated columns are subjected to elevated temperatures on the less stressed section of the column, thus the columns deflect toward the heat source. In the case of e $=25 \mathrm{~mm}$, the compressive stresses are not enough to counteract the effect of thermal expansion through the development of transient thermal creep. Still, the heat transfer inside the section may play a role, since as the heat reaches to the compressed fibres, where the compressive stresses are higher, transient thermal creep develops, thereby influencing the evolution of the deflections. Finally, higher loads in tensionheated columns result in lower stresses on the "tension face", thereby reducing the deflections.

\section{CONCLUSIONS}

From the extensive experimental campaign examined and the numerical analyses of the selected tested columns, several meaningful conclusions can be drawn about the structural behaviour of eccentrically loaded columns exposed to a localized heating. It was concluded, or to say confirmed, that the thermal gradient and stress state within the section are the two most important factors governing the response. In that regard, the most significant investigated parameters are:

- increasing the eccentricity of the applied load increases the moment induced by the load: as a result, if the stress on the heated face is large enough to cause transient thermal creep, the column will deflect away from the heat source during the whole fire duration. Otherwise, the influence of thermal expansion will dominate the response and the columns will bow towards the heat source;

- the magnitude of the imposed load will determine the stress state within the section and this will determine the extent of transient thermal creep through the depth of the section. This directly influences the direction in which the column will deflect: towards the heat source, in case the thermal expansion governs the problem (low compressive stresses at the exposed sides) or away 
from the heat source (when the compressive stresses at the exposed sides are large enough to counteract the effect of thermal expansion);

- heat flux is a parameter of utmost importance, as it determines the temperature gradient within the structural member and thus it has a strong impact on the structural response. The higher the temperature inside the member, the more the concrete will be weakened and the greater nonrecoverable deformations as a result of increased transient thermal creep resulting both from the elevated temperature and stress distribution through the section;

- the structural response can be very different depending on which side of the member is heated the most stressed side or the least stressed side. This can even determine if the column will survive heating and cooling or will collapse.
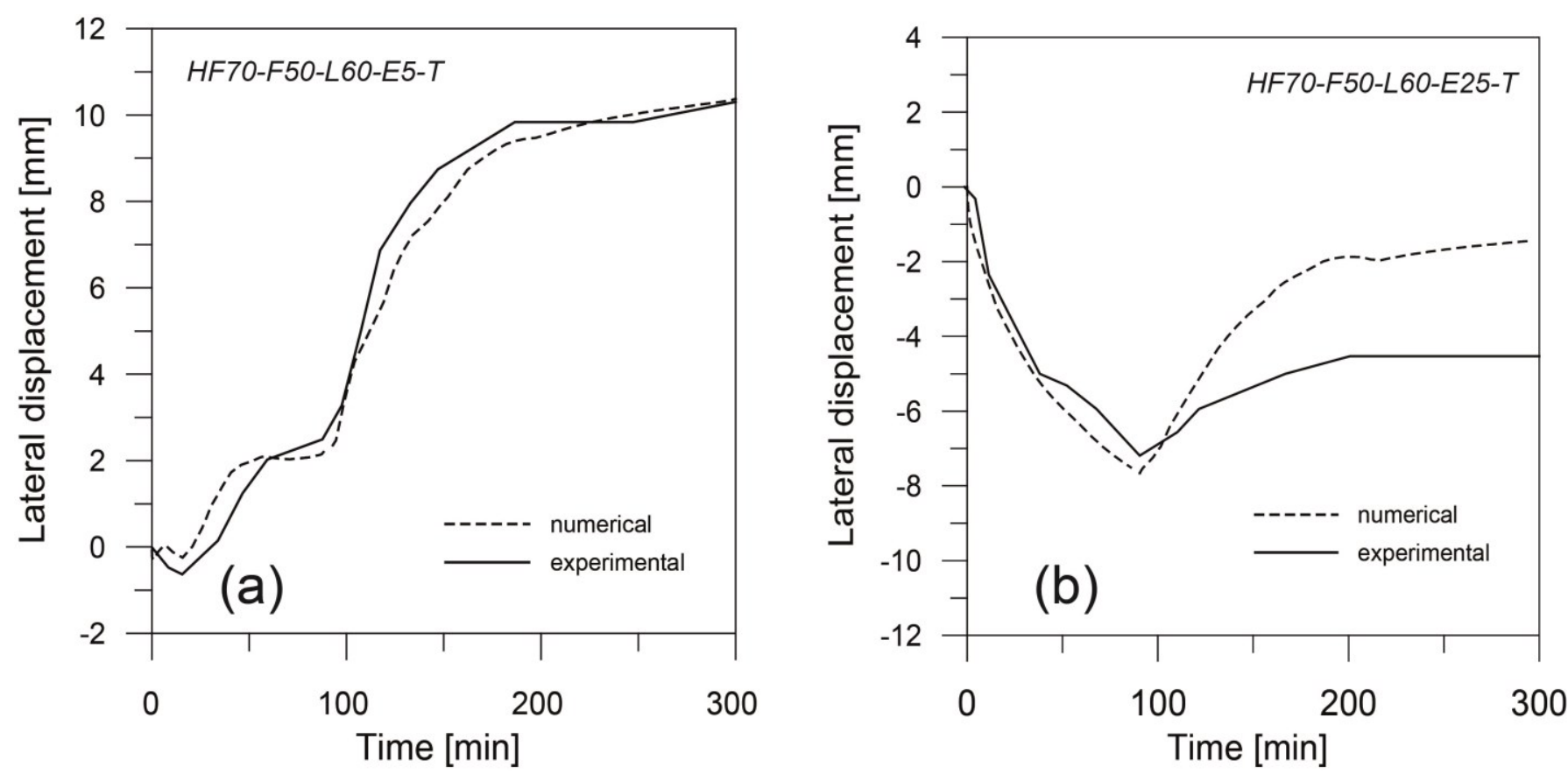

Figure 9. Comparison between experimental and numerical midspan deflection evolution for heavily-loaded columns with compressive strength $\mathrm{f}_{\mathrm{c}}=50 \mathrm{MPa}$ : (a) tension-heated, $\mathrm{e}=5 \mathrm{~mm}$ and (b) tension-heated, $\mathrm{e}=25 \mathrm{~mm}$

\section{REFERENCES}

1. Bamonte, P. and Lo Monte, F., Reinforced concrete columns exposed to standard fire: comparison among different constitutive models for concrete at high temperature, Fire Safety Journal, Vol. 71, 2015, pp. 310323.

2. EN 1991-1-2, Eurocode 1: Actions on structures - Part 1-2: General actions - Actions on structures exposed to fire, European Committee for Standardization, Brussels (Belgium), 2002.

3. EN 1992-1-2, Eurocode 2: Design of concrete structures - Part 1-2: General rules - Structural fire design, European Committee for Standardization, Brussels (Belgium), 2004.

4. Gernay, T., Fire resistance and burnout resistance of reinforced concrete columns, Fire Safety Journal, Vol. 104, 2019, pp. 67-78.

5. Kalaba, N., On the role of materials properties and structural context in reinforced concrete members exposed to natural fires, PhD Thesis, Politecnico di Milano (Milan, Italy), 2019.

6. Maclean, J., The Structural Response of Reinforced Concrete Columns During and After Exposure to NonUniform Heating and Cooling Regimes, PhD Thesis, University of Edinburgh (Edinburgh, UK), 2018.

7. Maclean, J. and Bisby, L., Effect of non-uniform heating and cooling on eccentrically loaded reinforced concrete columns, Proceedings of the 11th International Conference on Structures in Fire - SiF 2020, hosted online by the University of Queensland (Brisbane, AUS), $30^{\text {th }}$ November $-2^{\text {nd }}$ December 2020. 